\title{
Increased Expression of Complement Decay-accelerating Factor during Activation of Human Neutrophils
}

\author{
Melvin Berger and M. Edward Medof \\ Departments of Pediatrics and Pathology, Case Western Reserve University School of Medicine, Cleveland, Ohio 44106
}

\begin{abstract}
Decay-accelerating factor (DAF) is a membrane protein that protects blood cells from damage by autologous complement. Using monoclonal antibodies in both direct-binding studies and flow cytometry, we found that resting neutrophils (polymorphonuclear leukocytes [PMN]) expressed $10^{4}$ DAF molecules on their surface, and that surface DAF expression more than doubled when the cells were activated. Upregulation of surface DAF occurred within minutes, paralleled the upregulation of complement receptor types 1 and 3 (CR1 and CR3), and was not dependent on new protein synthesis. It was unaffected by EDTA but was inhibited by $10 \mu \mathrm{M}$ trifluoperazine, suggesting involvement of intracellular $\mathrm{Ca}^{2+}$ and calmodulin or protein kinase $\mathrm{C}$. Upon activation, the affected PMN lacking surface DAF from patients with paroxysmal nocturnal hemoglobulinuria failed to increase DAF expression. In contrast, these cells increased CR1 and CR3 expression normally, suggesting that DAF deficiency in affected cells involves abnormal synthesis or packaging of DAF for intracellular storage. Translocation of DAF to the cell surface induced by chemoattractants may be important in allowing PMN to survive and function at inflammatory sites where there is rapid complement turnover.
\end{abstract}

\section{Introduction}

Decay-accelerating factor (DAF) ${ }^{1}$ of human erythrocytes $(E)$ is a 70-75-kD surface protein which interacts with autologous $\mathrm{C} 4 \mathrm{~b}$ and $\mathrm{C} 3 \mathrm{~b}$ fragments when they become attached to the $\mathrm{E}$ membrane. By blocking uptake of the second component of complement (C), C2, and factor B, DAF inhibits assembly of the classical as well as the alternative pathway $\mathrm{C} 3$ and $\mathrm{C} 5$ convertases and thus interferes with the amplification steps of the complement cascade (1-3). DAF thereby prevents hemolytic activity from developing at sites where small numbers of $\mathrm{C} 3 \mathrm{~b}$ or $\mathrm{C} 4 \mathrm{~b}$ molecules become attached either directly to $\mathrm{E}$, or indirectly to cells that are "bystanders" to the source of complement activation. Because DAF does not inhibit convertase formation on

Address reprint requests to Dr. Berger, Department of Pediatrics, Rainbow Babies' and Children's Hospital, Case Western Reserve University School of Medicine, 2101 Adelbert Road, Cleveland, $\mathrm{OH} 44106$.

Received for publication 30 June 1986.

1. Abbreviations used in this paper: $\mathrm{CR} 1$ and $\mathrm{CR} 3$, complement receptor types 1 and 3; DAF, decay-accelerating factor; E, erythrocyte(s); FITC, fluorescein isothiocyanate; fMLP, $N$-formyl-methionyl-leucyl-phenylalanine; PNH, paroxysmal nocturnal hemoglobinuria; ZAS, zymosanactivated serum.

J. Clin. Invest.

(c) The American Society for Clinical Investigation, Inc.

0021-9738/87/01/0214/07 \$1.00

Volume 79, January 1987, 214-220 soluble immune complexes, neighboring cells, or foreign particles, it is believed that its physiologic function is to protect host E from damage by autologous complement (3). This hypothesis is strengthened by observations that the complement-sensitive E from patients with paroxysmal nocturnal hemoglobinuria (PNH) are deficient in $\operatorname{DAF}(2,4,5)$, and that incorporation of purified DAF into the membranes of these cells ameliorates this abnormality (5).

Recent studies have demonstrated that DAF is also present on blood platelets, lymphocytes, monocytes, and neutrophils (polymorphonuclear leukocytes [PMN]) of normal individuals $(6,7)$. Comparison in a previous study of the content of DAF in cell extracts, as determined by immunoradiometric assay, with surface DAF expression, as determined by indirect immunofluorescence using monoclonal anti-DAF antibodies and flow cytometry, suggested that PMN contain more total DAF than is present on their surface membranes (6). These findings seemed analogous to results previously obtained for $\mathrm{C} 3 \mathrm{~b}$ and $\mathrm{iC} 3 \mathrm{~b}$ receptors (complement receptor types 1 and 3 [CR1 and CR3]), which have been shown to reside predominantly in intracellular pools in unstimulated circulating PMN (8-11). When the PMN are activated by chemoattractants, the intracellular CR1 and CR3 pools are rapidly translocated to the surface membrane by a process that does not require new protein synthesis (9-12). This translocation enhances the adherence and phagocytic activity of these cells as they move towards sites of infection (13).

Because increased amounts of "nascent" C4b and C3b molecules are likely to be present at inflammatory sites where complement activation is proceeding at a rapid rate, host PMN at these sites may be at increased risk for lysis by autologous complement. The present investigations were undertaken to determine whether the expression of DAF increases when PMN are activated. The results indicate that the amount of DAF expressed on the PMN surface rises at least twofold in response to complement activation products and other chemotactic stimuli. This increased DAF expression on PMN may be an important selfprotective mechanism allowing these cells to survive and function while moving towards sites of complement activation in the inflammatory milieu. The results additionally indicate that in $\mathrm{PNH}$, a disorder in which PMN are susceptible to uptake of increased amounts of autologous $\mathrm{C} 3 \mathrm{~b}$ (14) and because they are deficient in surface DAF $(6,15)$, affected cells are unable to augment DAF expression whereas they are able to increase CR 1 and CR3 expression in a normal fashion. These results argue that synthesis or packaging of DAF is abnormal and that accelerated loss of DAF from the cell membrane is not the primary mechanism of DAF deficiency in affected PNH cells.

\section{Methods}

Patients. P.K. is a 56-yr-old woman with severe disease lasting 36 yr. She had undergone splenectomy in another city before the diagnosis of PNH was established by the acid lysis test. She has been transfusion dependent, requiring more than $2 U$ of washed red cells every $3 \mathrm{mo}$. She 
has had regional enteritis in addition to several complications of her PNH and is currently treated with iron dextran injections, daily folate, and $5-10 \mathrm{mg} / \mathrm{d}$ prednisone.

M.W. is a 30-yr-old woman with anemia first recognized in 1982. She has had more mild disease, has not required routine transfusions, and is treated with daily folate and low doses of oral iron.

Complement lysis tests on blood samples from these patients were performed by Dr. Wendell Rosse, Duke University (16). P.K. was found to have $47 \%$ type III E (15-25-fold more sensitive than normal E), and M.W. was found to have $27 \%$ type II E (3-5-fold more sensitive than normal E).

Leukocyte isolation and incubation. PMN were isolated from freshly drawn heparinized blood of normal donors and patients as described previously (9). Briefly, the blood was layered over density gradients (17) of Percoll (Pharmacia Fine Chemicals, Piscataway, NJ) and centrifuged at $300 \mathrm{~g}$ at $14^{\circ} \mathrm{C}$ for $17 \mathrm{~min}$. E were removed by two cycles of lysis using ice-cold $0.2 \% \mathrm{NaCl}$ followed by addition of $1.6 \% \mathrm{NaCl}$. The leukocyte pellet was washed with Hank's balanced salts solution (HBSS) without $\mathrm{Ca}^{2+}, \mathrm{Mg}^{2+}$, or phenol red. The preparations generally contained $>95 \%$ PMN of which $>98 \%$ excluded trypan blue. The PMN fraction of patient P.K., with severe PNH, contained $10 \% \mathrm{E}$, which were larger and less dense than normal and some of which were nucleated. Leukocytes were suspended at $1-3 \times 10^{6} / \mathrm{ml}$ in HBSS containing $0.1 \%$ gelatin and incubated at $37^{\circ} \mathrm{C}$ for $1 \mathrm{~h}$ in the presence of various activators and/or inhibitors, with gentle vortexing every $10 \mathrm{~min}$. Control aliquots of the same suspension were maintained on ice for the same interval.

Activators and inhibitors. $\boldsymbol{N}$-formyl-methionyl-leucyl-phenylalanine (fMLP) was obtained from Peninsula Laboratories Inc. (Belmont, CA) and stored at $-70^{\circ} \mathrm{C}$ as a $10^{-3} \mathrm{M}$ stock solution in dimethyl sulfoxide. Unless otherwise indicated, fMLP was used at $10^{-8} \mathrm{M}$. Freshly drawn serum from an $\mathbf{A B}$ donor was activated with zymosan as previously described (18) and stored in aliquots at $-70^{\circ} \mathrm{C}$. The zymosan-activated serum (ZAS) was used at a final dilution of 1:100. Cycloheximide, puromycin, and phenylmethylsulfonyl fluoride (PMSF) were obtained from Sigma Chemical Co. (St. Louis, MO) and trifluoperazine from Smith, Kline and French (Philadelphia, PA).

Monoclonal antibodies and fluorescent conjugates. Monoclonal antibody to CR1 (clone 3D9) was a gift of Dr. John O'Shea, National Institutes of Health, Bethesda, MD (11). Culture supernatant of the M1/ 70 hybridoma cell line (obtained from the American Type Culture Collection, Rockville, MD) producing antibody to the Mac-1 antigen, was used as anti-CR3 (19). Anti-DAF monoclonal antibodies IA 10 and IIH6 were obtained and purified as described previously (6). Fluorescein isothiocyanate (FITC)-conjugated $F\left(a b^{\prime}\right)_{2}$ fragments of goat anti-mouse IgG and anti-rat Ig were purchased from Cappel Laboratories, (Cochraneville, PA). All antibodies and conjugates were centrifuged at $110,000 \mathrm{~g}$ for 15 min in an airfuge (Beckman Instruments, Inc., Fullerton, CA) before each use.

Immunofluorescent staining and flow cytometry. Immunofluorescent staining was carried out with all steps performed at $0-4^{\circ} \mathrm{C}(9)$. Briefly, after incubation, PMN were divided into aliquots of $10^{6}$ cells, washed with HBSS containing $0.1 \%$ bovine serum albumin; $0.05 \% \mathrm{NaN}_{3}$, and $10^{-4} \mathrm{M}$ PMSF (HBSS +), and resuspended in $50 \mu \mathrm{l}$ of the same solution. Monoclonal antibodies were added in excess as determined in preliminary titration experiments, and the mixtures were incubated on a rotator for $30 \mathrm{~min}$. Cells were washed twice and resuspended in the same solution, excess FITC-F( $\left(a^{\prime}\right)_{2}$ anti-mouse IgG or anti-rat Ig conjugate was added, and incubation continued for another $30 \mathrm{~min}$. The stained cells were washed three times, then resuspended in phosphate-buffered saline containing $0.05 \% \mathrm{NaN}_{3}$ and held on ice until examination in the flow cytometer.

The fluorescence of 10,000 cells from each sample was determined by flow cytometry using a Becton-Dickinson FACS Analyzer (Becton, Dickinson \& Co., Sunnyvale, CA) standardized with $7.8-\mu \mathrm{m}$ diam fluorescent beads. The analyzer was operated with log-mode amplification, and the arithmetic mean linear equivalent fluorescence of each sample was computed automatically by the Consort 30 computer. Background fluorescence was determined using cells reacted with the FITC conjugate but no monoclonal antibody. This value was subtracted from all other determinations. Control experiments established that these background values did not differ from those obtained using isotype-matched, nonimmune monoclonals in the first step (9).

Binding studies with ${ }^{125}$ I-anti-DAF. Purified IIH6 anti-DAF monoclonal was labeled with ${ }^{125}$ I using Iodogen (Pierce Chemical Co., Rockland, IL) to a specific activity of $6 \times 10^{5} \mathrm{cpm} / \mu \mathrm{g}$. Varying amounts of 125I-labeled antibody $(0.01-0.20 \mu \mathrm{g})$ alone or with excess unlabeled antibody were diluted in a total volume of $0.1 \mathrm{ml}$ of HBSS + in $12 \times 75$ $\mathrm{mm}$ plastic culture tubes on ice. Aliquots of $0.1 \mathrm{ml}$ of PMN which had been washed and suspended at $20 \times 10^{6} / \mathrm{ml}$ after incubation were added, and the mixtures were vortexed briefly and incubated for $30 \mathrm{~min}$ at $4^{\circ} \mathrm{C}$ on a rotator. Duplicate $80-\mu 1$ aliquots were removed from each tube, layered over $250 \mu$ l of synthetic silicone oil, $d=1.050$ (General Electric Co., Waterford, NY) in $400-\mu l$ polypropylene centrifuge tubes and the cells were rapidly pelleted by centrifugation at $10,000 \mathrm{~g}$ for $2.5 \mathrm{~min}$ in a Beckman Instruments Microfuge B. $40 \mu$ l of the supernatant from each tube was counted to determine the amount of ${ }^{125}$ I-labeled antibody not bound. The remaining supernatant and most of the oil were aspirated and the tube was cut. The tip containing the cell pellet was counted to determine the bound radioactivity. Specific binding was determined by subtracting the radioactivity in the pellets of tubes containing 100 -fold excess of unlabeled antibody from the corresponding tubes containing ${ }^{125}$ I-labeled antibody alone. Counts of duplicate aliquots from each incubation were averaged and corrected back to the original total volume, and the data was analyzed by the method of Scatchard (20) using an Apple Ile computer (Cupertino, CA).

DAF contents in NP-40 extracts of PMN were determined using an immunoradiometric assay as previously described (6). The absolute concentration of the DAF standard was established by amino acid analysis.

\section{Results}

Quantitation of surface DAF expression on isolated PMN and correlation with fluorescence measurements. In order to quantify the number of DAF molecules on the surface of PMN, increasing amounts of ${ }^{125}$ I-anti-DAF monoclonal antibody IIH6 were incubated with the cells and both total and specific binding were determined. Results of a representative experiment are shown in Fig. $1 A$ and the corresponding Scatchard analysis is shown in Fig. $1 B$. In this study, which was performed on freshly isolated cells held in the resting state at $0^{\circ} \mathrm{C}$, the apparent dissociation constant was $1.6 \times 10^{-9} \mathrm{M}$ and the estimated number of sites
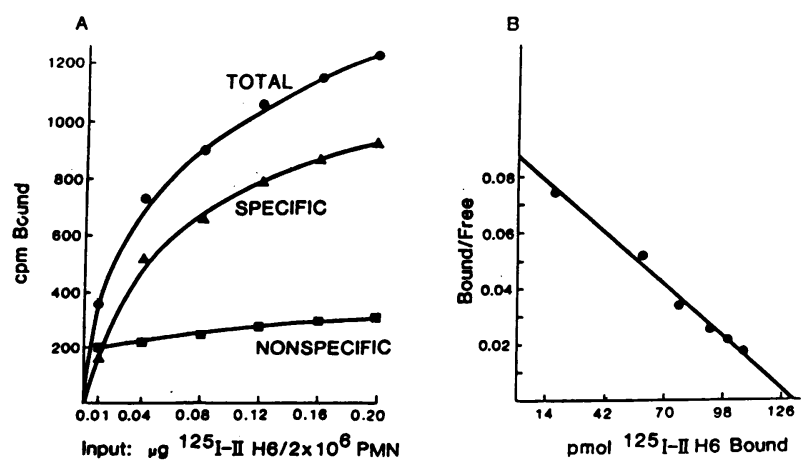

Figure 1. Quantitation of surface DAF on PMN by binding of ${ }^{125} \mathrm{I}$ anti-DAF. $(A)$ The results shown are the average of duplicate aliquots from the incubation mixtures at each input of labeled antibody. Nonspecific binding was determined in the presence of a 100 -fold excess of unlabeled antibody. Specific binding = total - nonspecific binding. All counts were corrected by subtracting background. $(B)$ Scatchard analysis of data from $A$. By linear regression, $K_{\mathrm{d}}=1.64 \times 10^{-9} \mathrm{M}$ and extrapolated binding at saturation $=8,540$ anti-DAF molecules per cell with $r=0.99$. 
at saturation was $8.5 \times 10^{3} /$ cell. The mean of the dissociation constants calculated from eight similar studies was 5.8 $\times 10^{-9} \mathrm{M}$.

To permit conversion of relative fluorescence intensity data obtained using flow cytometry to numbers of molecules per cell, immunofluorescent and direct-binding determinations were carried out in parallel on aliquots of cells from the same incubation mixtures. Monoclonal anti-DAF IA10 and FITC-conjugated $F\left(a b^{\prime}\right)_{2}$ anti-mouse IgG were used for the fluorescent analysis and ${ }^{125}$ I-IIH6 for the direct-binding determinations. As shown in Table I, the mean ( \pm SEM) level of DAF expression in resting cells as determined by the direct-binding method was $9,740 \pm 1,070$ molecules per cell, and in activated cells was $22,700 \pm 720$ molecules of DAF per cell. The comparative ratios of surface DAF on activated to resting cells obtained with relative fluorescence measurements, 2.58, and direct binding determinations, 2.33 , were in close agreement. When subjected to linear regression analysis, the correlation coefficient $(r)$ was 0.97 .

Surface DAF expression on isolated PMN held at $0^{\circ} \mathrm{C}$ and effect of temperature. Previous studies of isolated PMN held at $0^{\circ} \mathrm{C}$ have shown that resting PMN express $\sim 6,000 \mathrm{CR} 1$ and 17,000 CR3 molecules/cell $(8,9)$. Studies of isolated PMN at $0^{\circ} \mathrm{C}$ using anti-DAF monoclonals are shown in the left group of bars in Fig. 2 in relation to control studies using anti-CR 1 and anti-CR3 monoclonals. As can be seen, higher fluorescence on resting cells at $0^{\circ} \mathrm{C}$ was obtained with anti-DAF than with the antibodies to either of the complement receptors. Because CR1 and DAF were stained with the same FITC-conjugate, the relative fluorescent intensities reflect the relative numbers of each protein, assuming one antibody molecule binds to each protein molecule $(6,9,12)$. The value obtained for DAF, 3.53 \pm 0.38 , (mean \pm SEM, $n=7$ ) was 2.2 times higher than that for CR1, $1.59 \pm 0.51$ in this series of determinations.

The effect of temperature on DAF expression on the isolated PMN was evaluated next. As shown in Fig. 2, surface DAF levels increased 1.47 -fold when the cells were warmed from $0^{\circ} \mathrm{C}$ to $37^{\circ} \mathrm{C}$. This increase resembled the increases in CR1 and CR3 expression which have been observed when buffy coat cells or PMN isolated by centrifugation are warmed to $37^{\circ} \mathrm{C}$ in the absence of chemical stimuli (8-10). In the determinations of CR1 and CR3 expression performed here in parallel to the analyses

Table I. Quantitation of DAF Expression on Resting and Activated Isolated PMN

\begin{tabular}{llll}
\hline & $\begin{array}{l}\text { Mean } \\
\text { fluorescence }\end{array}$ & $\begin{array}{l}\text { 125I-anti-DAF } \\
\text { sites/cell }\end{array}$ & $n$ \\
\hline $\begin{array}{l}\text { Resting: } 0^{\circ} \mathrm{C} \text { in } \\
\text { HBSS/gel }\end{array}$ & $5.99 \pm 0.34$ & $9,740 \pm 1,074$ & 4 \\
$\begin{array}{l}\text { Stimulated: fMLP } \\
\quad 10^{-8} \mathrm{M}\end{array}$ & $15.44 \pm 0.90$ & $22,700 \pm 719$ & 3 \\
$\begin{array}{l}\text { Ratio of means: } \\
\text { Stimulated/Resting }\end{array}$ & 2.58 & 2.33 & \\
\end{tabular}

Aliquots of each cell suspension were split: $2 \times 10^{6}$ cells were used for fluorescence analysis and $24 \times 10^{6}$ were used for direct binding study. Results shown are mean \pm SEM for the number of experiments indicated. Fluorescence was corrected for background and autofluorescence using FITC conjugate but without monoclonal anti-DAF. Scatchard analysis of ${ }^{125}$ I-binding data was performed as in Fig. 1. Linear regression analysis of mean fluorescence vs. ${ }^{125}$ I binding had $r=0.97$.

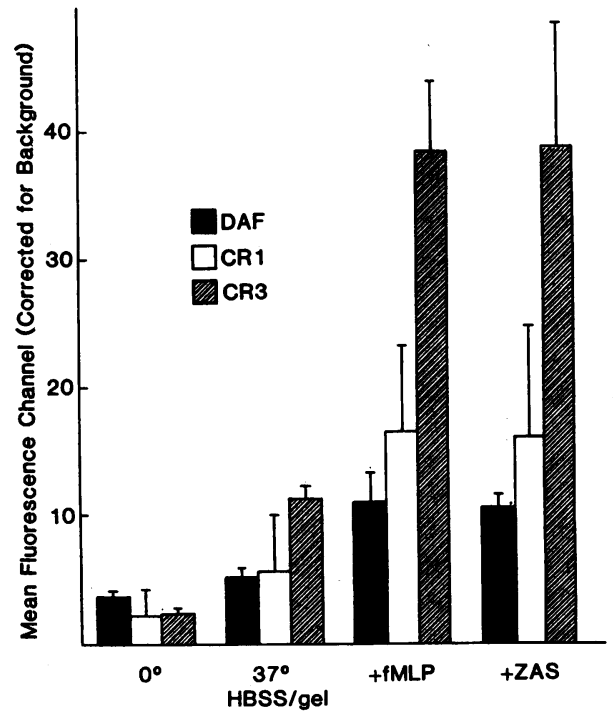

Figure 2. Comparison of DAF, CR1, and CR3 expression on resting and stimulated isolated PMN. Cells were incubated under the designated conditions for $1 \mathrm{~h}$ before washing and immunofluorescent staining. Background fluorescence was subtracted from all values as described in the Methods. Results shown are the means \pm SEM of the fluorescence of 10,000 cells determined in each of seven experiments. The $\mathrm{fMLP}$ concentration was $10^{-8} \mathrm{M}$ and ZAS was used at 1:100 final dilution. Temperatures are given in ${ }^{\circ} \mathrm{C}$.

of DAF, the mean levels of the two receptors increased 2.75and 4.56-fold, respectively.

Increased surface DAF expression induced by chemoattractants. DAF levels on PMN after stimulation with IMLP or ZAS were next measured as shown in the right half of Fig. 2. Compared with cells held at $37^{\circ} \mathrm{C}$ in medium alone, cells treated with $10^{-8} \mathrm{M}$ fMLP showed a further $2.13 \pm 0.48$-fold increase in DAF expression. Binding studies with ${ }^{125}$ I-anti-DAF monoclonal IIH6 demonstrated that this level of fluorescence corresponded to $22,700 \pm 720$ DAF molecules per cell (mean \pm SEM, $n=3$ ). Cells treated with ZAS, a source of C5a des-Arg, showed a 2.08 \pm 0.15 -fold increase in DAF fluorescence. Quantitation of total DAF in extracts of similar cell preparations by immunoradiometric assay revealed $18,000 \pm 1,000$ (mean $\pm \mathrm{SEM}, n=8$ ) molecules per cell, with an additional 1,800-3,000 molecules per cell remaining insoluble. In the same experiments, fMLP induced 3.82- and 3.41-fold increases in CR1 and CR3 expression whereas ZAS increased surface CR1 and CR3 3.47- and 3.46-fold, respectively.

The time course and dose response for the effects of IMLP on DAF expression are shown in Fig. 3. DAF expression increased to $80 \%$ of maximum within $10 \mathrm{~min}$ after addition of $10^{-8} \mathrm{M}$ fMLP. Cells examined $60 \mathrm{~min}$ after addition of the peptide continued to show near-maximal DAF expression. $10^{-10} \mathrm{M}$ fMLP had no discernable effect whereas $10^{-9} \mathrm{M}$ gave about half of the maximal response, which was observed at $10^{-8} \mathrm{M}$. Higher concentrations caused $\sim 10 \%$ less DAF expression. The doseresponse curves for $\mathrm{CR} 1$ and $\mathrm{CR} 3$ generated in the same experiments were parallel to that shown for DAF.

Effect of protein synthesis inhibitors and possible role of $\mathrm{Ca}^{2+}$ in augmenting DAF expression. The rapidity with which the expression of DAF increased in response to the above stimuli, together with the previous demonstration of a large excess of 

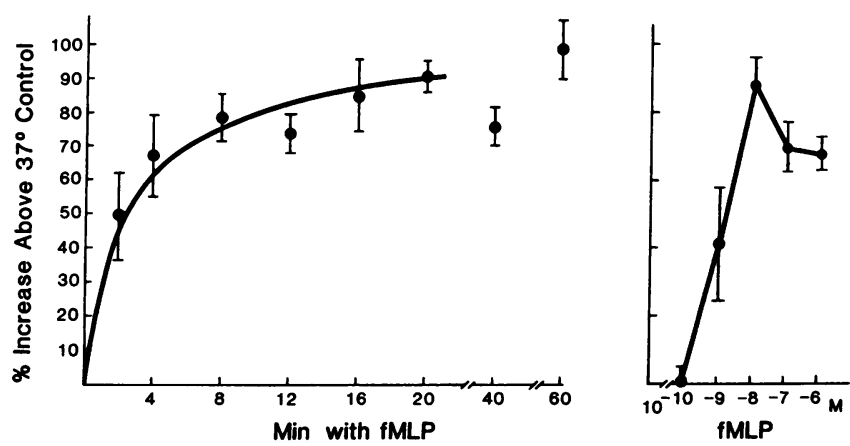

Figure 3. Time course and dose response of increased DAF expression induced by fMLP. (Left) PMN were incubated in HBSS with $0.1 \%$ gelatin for $1 \mathrm{~h}$ at $37^{\circ} \mathrm{C}$ and $10^{-8} \mathrm{M}$ fMLP was added for the indicated length of time. All incubations were terminated at the same time and cells were washed and prepared for flow cytometry. Results are expressed as the mean + SEM for three to five experiments. The increase in mean fluorescence is given in comparison to control cells that were held at $37^{\circ} \mathrm{C}$ without fMLP. The mean $( \pm S E M)$ fluorescence for DAF expression on the $37^{\circ} \mathrm{C}$ control cells was $1.9 \pm .38$-fold higher than that on cells held at $0^{\circ} \mathrm{C}$. (Right) Similar data for the addition of the indicated concentration of PMLP for $60 \mathrm{~min}$.

DAF antigen in PMN extracts not detectable on the PMN surface suggested that augmented DAF expression might involve translocation of DAF from an intracellular pool rather than new DAF synthesis. We therefore determined the effects of protein synthesis inhibitors. The increase in DAF expression induced by $\mathrm{fMLP}, 197 \pm 6 \%(n=5)$ was not altered by the addition of $10 \mu \mathrm{g} / \mathrm{ml}$ of cycloheximide, $203 \pm 14 \%(n=3)$, or puromycin, $202 \pm 13 \%(n=4)$. Similar results were obtained with ZAS. This is consistent with the hypothesis that new protein synthesis is not required.

The effects of agents which modulate extra- and intracellular $\mathrm{Ca}^{2+}$ levels were investigated next. The results shown in Fig. 4 indicate that adding neither $1.2 \mathrm{mM} \mathrm{CaCl} 2$ nor $5 \mathrm{mM}$ EDTA to media initially free of divalent cations had any effect on the augmentation of DAF expression by fMLP. In contrast, $10 \mu \mathrm{M}$

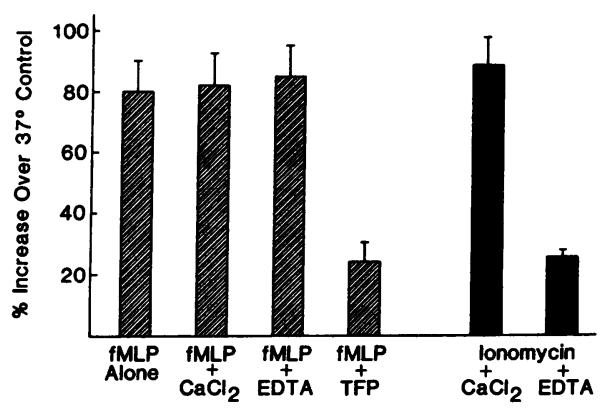

Figure 4. Effects of drugs that influence $\mathrm{Ca}^{2+}$ on increased DAF expression induced by fMLP. Isolated PMN were incubated at 1.5 $\times 10^{6} / \mathrm{ml}$ in HBSS-gelatin initially free of divalent cations for $60 \mathrm{~min}$ at $37^{\circ} \mathrm{C}$ alone, with $10^{-8} \mathrm{M} \mathrm{fMLP}$, or with $10^{-7} \mathrm{M}$ ionomycin and 1.2 $\mathrm{mM} \mathrm{CaCl}{ }_{2}$. Results are compared with cells held in HBSS-gelatin alone and are the means \pm SEM for three to five experiments for each condition. The fluorescence of the $37^{\circ} \mathrm{C}$ control cells was $1.52 \pm .12$ fold increased over $0^{\circ} \mathrm{C}$ cells. Final concentrations of additions were: $\mathrm{CaCl}_{2} 1.2 \mathrm{mM}$, EDTA $5 \mathrm{mM}$, trifluoperazine (TFP) $10 \mu \mathrm{M} . P$ values by Student's $t$ test were $<0.01$ for effect of TFP on AMLP and for effect of EDTA on ionomycin. trifluoperazine caused significant inhibition $(P<0.01)$, suggesting a role for intracellular $\mathrm{Ca}^{2+}$ and calmodulin and/or protein kinase $\mathrm{C}$. To further evaluate this possibility, ionomycin, an agent which bypasses the physiologic signal-transducing mechanisms, was used to increase the intracellular $\mathrm{Ca}^{2+}$ concentration directly. As shown by the solid bars in Fig. 4, an increase in DAF expression resulted that was comparable to the increase induced by fMLP. In contrast to the fMLP effect, however, the effect of ionomycin was dependent on extracellular $\mathrm{Ca}^{2+}$ and was markedly inhibited by EDTA. These results parallel those previously reported for CR1 (21) and suggest that increased expression of DAF may similarly depend on the release of $\mathrm{Ca}^{2+}$ from intracellular stores rather than on the influx of extracellular $\mathrm{Ca}^{2+}$ which is also initiated by fMLP.

DAF expression on PMN from patients with $P N H$. Recent studies have shown that DAF is deficient in affected PMN of PNH patients $(6,15)$. In view of the above observations that a major portion of DAF in circulating PMN resides inside the cell rather than on the membrane, we next investigated whether PNH PMN could increase their DAF expression in response to activating stimuli. FACS Analyzer histograms of the immunofluorescence of PMN of a normal donor and two $\mathrm{PNH}$ patients are shown in Fig. 5. As seen in Fig. $5 A$, the PMN from the normal donor appeared as a single population with respect to DAF, CR1, and CR3 staining, and the expression of all three surface proteins increased in response to stimulation with fMLP. Fig. 5 $B$ shows parallel studies on PMN from a patient (M.W.) with type II E. Staining for DAF revealed two distinct populations of PMN, one with no fluorescence above background, and another which appeared to express a relatively normal amount of DAF in the resting state. When these cells were stimulated with fMLP, the DAF-negative population did not change while the mean fluorescence of the DAF-positive population increased from 13.9 to 20.1 . When corrected by subtracting the background fluorescence, this change represented a 1.6-fold increase, approximating that shown with PMN from normal individuals (see above). In contrast to the findings for DAF, this individual's PMN appeared as one homogeneous population with regard to CR 1 and CR 3 expression, and all cells increased these markers normally in response to stimulation. The results with PMN from a patient (P.K.) with type III E are shown in Fig. $5 C$. In distinction to patient M.W., with type II E described above, the resting PMN showed a single population with DAF fluorescence indistinguishable from background. There was little or no change in DAF expression when these cells were stimulated. As was the case with PMN from patient M.W., these cells appeared as a single population with regard to $C R 1$ and $C R 3$ expression, and the expression of both receptors increased normally after stimulation. The latter histograms show a small percentage of contaminating large erythrocytes which were not gated out and were revealed as negative when the CR1 and CR3 increased. Taken together, these results suggest that affected PMN in PNH not only lack surface DAF but are unable to increase DAF expression in response to activating stimuli.

\section{Discussion}

In this report, we present evidence that PMN contain intracellular DAF and that some of this DAF is rapidly brought to the PMN surface when the cells are activated. We found that $10^{4}$ DAF molecules are present on the surface of isolated PMN held at $0^{\circ} \mathrm{C}$, and that there is a small spontaneous increase in DAF 


\section{A. Normal Control}
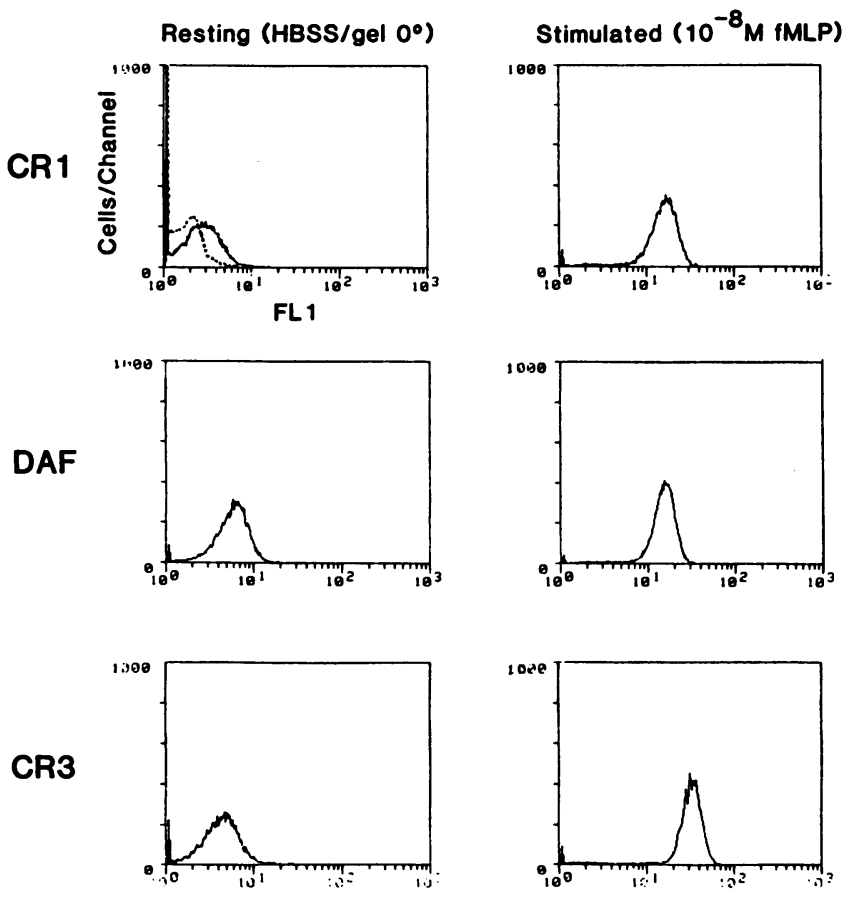

C. P.K. Type III E
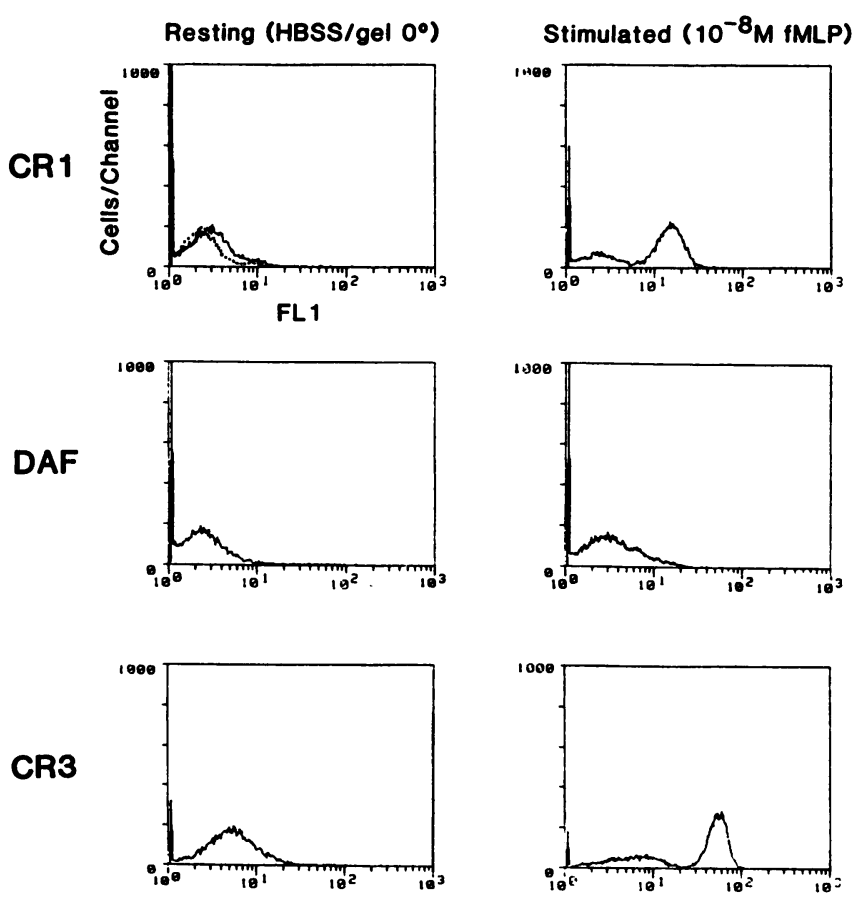

expression when isolated cells are subsequently placed at $37^{\circ} \mathrm{C}$ in the absence of stimuli. An additional twofold increase in DAF expression is induced by treatment with IMLP or with ZAS, a source of C5a des Arg. Maximal DAF expression occurs in minutes and is not inhibited by cycloheximide or puromycin. Thus it does not seem to involve protein synthesis. The maximum amount of DAF expressed on the cell surface in these studies,
B. M.W. Type II E
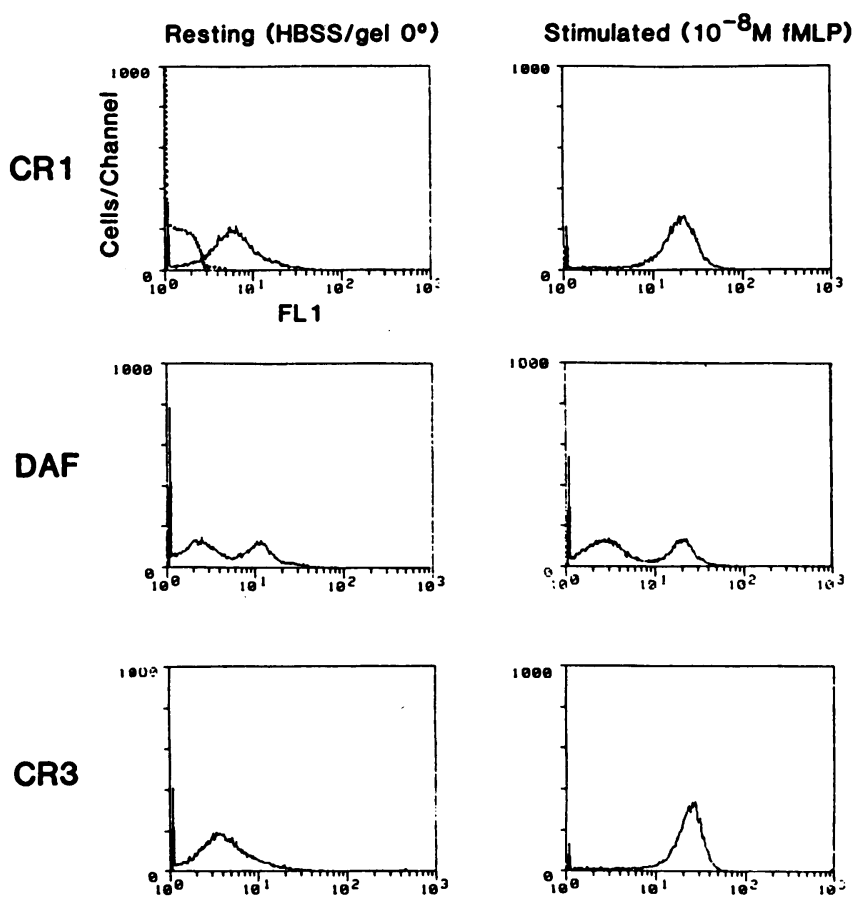

Figure 5. Fluorescence histograms of CR1, DAF, and CR3 expression on isolated PMN from $(A)$ a normal control and $(B, C)$ two PNH patients. $\mathrm{PMN}$ were incubated at $0^{\circ} \mathrm{C}$ (resting) or at $37^{\circ} \mathrm{C}$ for $1 \mathrm{~h}$ with $10^{-8} \mathrm{M}$ fMLP and washed, divided into aliquots, and stained separately for each surface protein. Results shown are the uncorrected histograms of 10,000 cells from each sample. Background fluorescence, assessed using FITC-F $\left(a b^{\prime}\right)_{2}$ anti-mouse IgG with no monoclonal antibody is shown by the dotted line in the upper left histogram for each individual. The background was not subtracted from the other histograms shown.

about 23,000 molecules per cell, corresponds to the total content of DAF in cell extracts. It thus seems likely that most or all of the intracellular DAF is available for translocation to the PMN surface in response to stimulation by optimal doses of fMLP or other activating agents.

It has been shown previously that, when human PMN are stimulated by chemoattractants or other activators, there is a 
rapid increase in the expression of $C R 1$ and $C R 3$, the receptors for the major opsonically active components of the complement system (8-13). The number of receptors for formyl-peptide chemoattractants also increases under these conditions (22). In addition to the appearance of these receptors on the membrane, there is an increase in the association with the membrane of protein kinase $C$ activity and of cytochrome b245, a component of the microbicidal oxidase system $(23,24)$. These alterations in membrane protein expression are specific, however, inasmuch as there is no concomitant change in the number of $\mathrm{Fc} \gamma$ receptors or in $\beta$-2-microglobulin expression (9). Thus, simple unfolding or ruffling of redundant membrane cannot account for these phenomena which are believed to be of critical importance in optimizing the function of the activated cell.

The intracellular pools of CR1 and CR3 are distinct from each other (11). Optimal CR3 expression is inhibited by EDTA and Mg-EGTA, whereas optimal CR1 expression requires intracellular $\mathrm{Ca}^{2+}$ but is not inhibited by these chelators (21), indicating that some of the reactions responsible for translocation of the two distinct receptor proteins to the surface are also apparently distinct. The characteristics of upregulation of DAF expression in response to chemoattractants are thus similar to those for CR1. The data suggest that induction of this translocation may involve intracellular $\mathrm{Ca}^{2+}$, in that this phenomenon is blocked by $10 \mu \mathrm{M}$ trifluoperazine, which inhibits calmodulin and/or protein kinase $C$-dependent processes $(25,26)$, but not by EDTA. Further evidence suggesting a role of $\mathrm{Ca}^{2+}$ is provided by the increase in DAF expression induced by ionomycin with $\mathrm{Ca}^{2+}$. There appears to be more DAF than CR1 on the surface of isolated PMN maintained at $0^{\circ} \mathrm{C}$ as judged both by relative fluorescence and by direct-binding studies of ${ }^{125} \mathrm{I}$-anti-DAF monoclonal antibodies. Recent studies have shown that E DAF differs from CR1 in that it is anchored to the membrane by a C-terminal glycolipid structure that is added to the DAF molecule during posttranslational processing (27). Determination of the relationship of the intracellular pool(s) of DAF to those of CR1 and CR3 and elucidation of the precise mechanism by which DAF is translocated to the surface membrane await further study.

Although the underlying defect in PNH is not yet clarified, the deficiency of DAF in E plays a major role in pathophysiology (1-7). Reconstitution of PNH E with DAF restores their ability to circumvent autologous $\mathrm{C} 3 \mathrm{~b}$ uptake and subsequent lysis (5). Immunochemical analyses have demonstrated that DAF is deficient in PMN of all PNH patients studied to date $(4,6)$. In the two PNH patients described in this study, this was also the case, and the percentage of DAF-negative circulating PMN was much greater in the patient with type III E. It is possible that circulating PMN of PNH patients could lose surface DAF while retaining their intracellular pool or that affected PMN could generate new DAF upon activation. The results clearly indicate that DAF expression on initially negative cells does not increase when they are stimulated. In contrast, both CR 1 and CR3 expression on the DAF-deficient cells appear to increase normally. Interestingly, in the patient whose PMN showed two distinct populations when stained for DAF, the same cells appeared homogeneous when stained for CR1 and CR3, and the population of initially DAFpositive PMN further increased DAF expression normally after stimulation. Thus, circulating PMN that are deficient in surface DAF also appear to be deficient in intracellular DAF, suggesting that the deficiency occurs at the time of synthesis or packaging of DAF for intracellular storage. Accelerated loss of DAF from the membrane is therefore unlikely to account for the deficiency of DAF in affected cells.

Because PMN must migrate to and function in inflammatory sites where complement consumption is proceeding at rapid rates, it seems advantageous that the expression of DAF on their membranes should increase in response to chemoattractants. The major function of DAF is believed to be protection of the cell against damage by autologous complement. Such damage could certainly occur if increased amounts of $\mathrm{C} 4 \mathrm{~b}$ and $\mathrm{C} 3 \mathrm{~b}$, generated by convertases on other cells and/or in the fluid phase, became deposited on the infiltrating host PMN, and served as sites for formation of additional convertase activity. This amplification is specifically inhibited by DAF. The increased expression of DAF under these conditions may thus be important in allowing the PMN to survive and function at sites of infection and inflammation.

\section{Acknowledgments}

We thank Dr. Russell Weisman, Jr. for providing blood samples from his patients and for helpful discussions and Elizabeth $I$. Walter and Erica M. Wetzler for expert technical assistance.

This study was supported by grant AI-22800 from the National Institutes of Health and by the American Diabetes Association, The Arthritis Foundation, and the Children's Research Foundation of Cleveland.

\section{References}

1. Nicholson-Weller, A., J. Burge, D. T. Fearon, P. F. Weller, and K. F. Austen. 1982. Isolation of a human erythrocyte membrane glycoprotein with decay-accelerating activity for $\mathrm{C} 3$ convertases of the complement system. J. Immunol. 129:184-189.

2. Pangburn, M. K., R. D. Schreiber, and H. J. Mueller-Eberhard. 1983. Deficiency of an erythrocyte membrane protein with complement regulatory activity in paroxysmal nocturnal hemoglobinuria. Proc. Natl. Acad. Sci. USA. 80:5430-5434.

3. Medof, M. E., T. Kinoshita, and V. Nussenzweig. 1984. Inhibition of complement activation on the surface of cells after incorporation of decay-accelerating factor (DAF) into their membranes. J. Exp. Med. 160:1558-1578.

4. Nicholson-Weller, A., J. P. March, S. I. Rosenfeld, and K. F. Austen. 1983. Affected erythrocytes of patients with paroxysmal nocturnal hemoglobinuria are deficient in the complement regulatory protein, decay accelerating factor. Proc. Natl. Acad. Sci. USA. 80:5066-5070.

5. Medof, M. E., T. Kinoshita, R. Silber, and V. Nussenzweig. 1985. Amelioration of the lytic abnormalities of paroxysmal nocturnal hemoglobinuria with decay accelerating factor. Proc. Natl. Acad. Sci. USA. 82:2980-2984.

6. Kinoshita, T., M. E. Medof, R. Silber, and V. Nussenzweig. 1985. Distribution of decay-accelerating factor in the peripheral blood of normal individuals and patients with paroxysmal nocturnal hemoglobinuria. $J$. Exp. Med. 162:75-92.

7. Nicholson-Weller, A., J. P. March, C. E. Rosen, D. B. Spicer, and K. F. Austen. 1985. Surface membrane expression by human blood leukocytes and platelets of decay-accelerating factor, a regulatory protein of the complement system. Blood. 65:1237-1244.

8. Fearon, D. T., and L. A. Collins. 1983. Increased expression of $\mathrm{C} 3 \mathrm{~b}$ receptors on polymorphonuclear leukocytes induced by chemotactic factors and by purification procedures. J. Immunol. 130:370-375.

9. Berger, M., J. J. O’Shea, A. S. Cross, T. M. Folks, T. L. Chused, E. J. Brown, and M. M. Frank. 1984. Human neutrophils increase expression of C3bi as well as C3b receptors upon activation. J. Clin. Invest. 74:1566-1571.

10. Todd, R. F., M. A. Arnaout, R. E. Rosin, C. A. Crowley, W. A. Peters, and B. M. Babior. 1984. Subcellular localization of the large subunit of Mol, a surface glycoprotein associated with neutrophil adhesion. J. Clin. Invest. 74:1280-1290. 
11. O’Shea, J. J., E. J. Brown, B. E. Seligman, J. A. Metcalf, M. M. Frank, and J. I. Gallin. 1985. Evidence for distinct intracellular pools of receptors for $\mathrm{C} 3 \mathrm{~b}$ and $\mathrm{C} 3 \mathrm{bi}$ in human neutrophils. J. Immunol. 134: 2580-2587.

12. Berger, M., and A. S. Cross. 1984. Lymphoblastoid cell supernatants increase expression of $\mathrm{C} 3 \mathrm{~b}$ receptors on human polymorphonuclear leukocytes: direct binding studies with ${ }^{125} \mathrm{I}-\mathrm{C} 3 \mathrm{~b}$. Immunology. 51:431-440.

13. Kay, A. B., J. Glass, and D. McG. Salter. 1979. Leucoattractants enhance complement receptors on human phagocytic cells. Clin. Exp. Immunol. 38:294-299.

14. Stern, M., and W. F. Rosse. 1979. Two populations of granulocytes in paroxysmal nocturnal hemoglobinuria. Blood. 53:928-934.

15. Nicholson-Weller, A., D. B. Spicer, and K. F. Austen. 1985. Deficiency of the complement regulatory protein, "decay accelerating factor" on the membranes of granulocytes, monocytes and platelets in paroxysmal nocturnal hemoglobinuria. N. Engl. J. Med. 312:1091-1097.

16. Rosse, W. F., J. P. Adams, and A. M. Thorpe. 1974. The population of cells in paroxysmal nocturnal haemoglobinuria of intermittent sensitivity in complement lysis. Br. J. Haematol. 28:181-190.

17. Harbeck, R. J., A. A. Hoffman, S. Redecker, T. Biundo, and J. Kurnick. 1982. The isolation and functional activity of polymorphonuclear leukocytes and lymphocytes separated from whole blood on a single Percoll density gradient. Clin. Immunol. Immunopathol. 23:682690.

18. Craddock, P. R., J. Fehr, A. Dalmasso, K. Brigham, and H. Jacob. 1977. Hemodialysis leukopenia: pulmonary vascular leukostasis resulting from complement activation by dialyzer cellophane membranes. J. Clin. Invest. 59:379-388.
19. Beller, D. I., T. A. Springer, and R. D. Schreiber. 1982. AntiMac 1 selectively inhibits the mouse and human type three complement receptor. J. Exp. Med. 156:1000-1009.

20. Scatchard, G. 1949. The attraction of proteins for small molecules and ions. Ann. N.Y. Acad. Sci. 51:660-672.

21. Berger, M., D. L. Birx, E. M. Wetzler, J. J. O’Shea, E. J. Brown, and A. S. Cross. 1985. Calcium requirements for increased complement receptor expression during neutrophil activation. J. Immunol. 135:13421348.

22. Fletcher, M. P., and J. I. Gallin. 1983. Human neutrophils contain an intracellular pool of putative receptors for the chemoattractant $\mathrm{N}$ formyl-methionyl-leucyl-phenylalanine. Blood. 62:792-799.

23. McPhail, L. C., C. C. Clayton, and R. Snyderman. 1984. A potential second messenger role for unsaturated fatty acids: activation and modulation of $\mathrm{Ca}^{2+}$-dependent protein kinase. Science (Wash. DC). 224: 622-625.

24. Borregaard, N., J. M. Heiple, E. R. Simons, and R. A. Clark. 1983. Subcellular localization of the B-cytochrome component of the human neutrophil microbicidal oxidase: translocation during activation. J. Cell. Biol. 97:52-61.

25. Weiss, B. 1983. Techniques for measuring the interaction of drugs with calmodulin. Methods Enzymol. 102:171-184.

26. Mori, T., Y. Takai, R. Minakuchi, B. Yu, and Y. Nichizuka. 1980. Inhibitory action of chlorpromazine, dibucaine, and other phospholipid-interacting drugs on calcium-activated phospholipid-dependent protein kinase. J. Biol. Chem. 255:8378-8380.

27. Medof, M. E., E. I. Walter, W. L. Roberts, R. Haas, and T. L. Rosenberry. 1986. The decay-accelerating factor of complement is anchored to cells by a c-terminal glycolipid. Biochemistry. 25:6740-6747. 